\title{
Editorial: Warnock, 40 Years On: Challenges for Special Educational Needs
}

\author{
Geoff Lindsay ${ }^{1 *}$, Klaus Wedell ${ }^{2}$ and Julie Elizabeth Dockrell ${ }^{2}$ \\ ${ }^{1}$ Centre for Educational Development, Appraisal and Research (CEDAR), University of Warwick, Coventry, United Kingdom, \\ ${ }^{2}$ Institute of Education, University College London, London, United Kingdom
}

Keywords: special educational needs (SEN), special educational needs and disability (SEND), parents and SEND, special educational needs coordinators (SENCOS), SEN disagreement resolution, disproportionality, inclusion, special education provision

\section{Editorial on the Research Topic}

\section{Warnock 40 Years On}

In 2019, a year after the 40th anniversary commemoration of the publication of the Report on the Enquiry into Special Educational Needs (SEN) for the UK government in 1978, Mary Warnock (then Baroness) died aged 94. Through her chairing of the 26 member Committee, its report had come to be called the "Warnock Report." The Warnock Report (Department for Education

Edited by:

Susana Castro-Kemp, University of Roehampton London, United Kingdom

Reviewed by:

Lorella Terzi,

University of Roehampton London, United Kingdom

${ }^{*}$ Correspondence:

Geoff Lindsay geoff.lindsay@warwick.ac.uk

Specialty section

This article was submitted to Special Educational Needs, a section of the journal Frontiers in Education

Received: 04 December 2019 Accepted: 23 January 2020

Published: 11 February 2020

Citation:

Lindsay G, Wedell K and Dockrell JE

(2020) Editorial: Warnock, 40 Years

On: Challenges for Special

Educational Needs. Front. Educ. 5:10.

doi: 10.3389/feduc.2020.00010
\& Science, 1978) has had massive influence on the development, conceptualization, policy, and practice for children and young people with SEN both nationally and internationally.

In an interview in 2018 (Webster, 2019, p. 11), Mary Warnock was asked how she had come to be selected to be chair, she replied:

"I'd been the headmistress of an [academically high achieving] school and was thought to be interested in education... So I came with perhaps a useful ignorance of the whole subject."

She had been a tutor in Philosophy at Oxford University.

The report was widely anticipated, because it had been set up as the result extensive lobbying pressure by both professionals and parents in the preceding 10 years. It established the significant developments in policy and practice which had been achieved during these years, and significantly had completely overtaken the (by then) outdated terms of reference given to the Committee by the government. So chairing the Committee must have presented a steep learning curve for her.

In the subsequent 40 years, Mary Warnock became regarded as the proponent of her Committee's recommendations, and was consulted in many legislative revisions on special education undertaken by successive governments. In 2007, she herself initiated a critical review of some of the inclusive recommendations derived from the Committee's Report (Warnock, 2005). Although, Mary Warnock had become involved in other Enquiries, she still acted in support of those concerned in developing special needs principles and practice, and maintained the pressure for adequate government funding.

This e-book was developed in order to take stock of the legacy from the Warnock Report, to examine where we are now with SEN and also consider ideas for the future. The e-book comprises 16 papers which were accepted from those submitted to an open invitation and which were subject to the normal refereeing procedure. Our thanks to all authors and to those who willingly gave of their time to act as associate editors and review editors. 


\section{CONTENTS}

The papers in this Research Topic cover a wide range of topics. Some are directly related to issues raised in the Warnock Report, e.g., SEN policy, others address issues that have arisen subsequently, e.g., the contribution of teaching assistants and special educational needs coordinators (SENCOs) in schools. The first paper provides an overview of the Research Topic as a whole, written by the editors (Lindsay et al.). This paper relates how each other constituent paper is related to both the Warnock Report and also to other current research literature.

Norwich argues that there is a strong interconnection between SEN and inclusion with broader aspects of educational policy and provision and that, consequently, SEN policy development depends on general policy processes. Norwich proposes an Education Framework Commission which has the potential to reconcile the many, sometimes contrary value positions. These are exemplified by Daniels et al. in terms of policies promoting competition between schools, in tension with the development of inclusive education. Daniels et al., argue that in England there are perverse incentives for schools not to meet students' SEN, which can result in exclusion from school.

Support for these critiques is presented in several papers. First, the scene is set by Black who examines the national SEN statistics for England, including the numbers and percentages of school students with SEN, the relationship with demographics including social disadvantage, and the increase in the numbers of both special schools, and of education, health and care (EHC) plans under the Children \& Families Act 2014. Lamb critically reviews the development of the SEN system from the Warnock Report to the Children \& Families Act 2014, in particular the establishment in law of levels of resource for children with complex SEN, initially through statements of SEN and now through EHC plans. He argues for the importance of parental confidence in the SEN system and the need for improvements in the quality of the non-statutory offer for children and young people with SEN but not EHC plans. Castro-Kemp et al. extend these concerns, finding that the quality of the outcomes in the EHC plans they reviewed was low.

Cullen and Lindsay address disagreement resolution where parents of children and young people with SEN were highly dissatisfied with the provision made or being sought. Based on in-depth interviews, the study revealed that disagreements were initially driven by their concern that their child's SEN were not being met and by their subsequent dissatisfaction with the SEND system, e.g., its delays, and their experiences of trying to get their children's SEN met.

Other papers report findings which extend the concerns about the current SEND system. Dockrell et al. report a study of students with either developmental language disorder or autism spectrum disorder. A key argument in the Warnock Report had been to move away from diagnostic labels to determine provision by need but Dockrell et al. found the opposite: provision was being driven by diagnostic labels rather than need. In this case, students with ASD were more likely to receive support from school and also by speech and language therapists than those with DLD. Furthermore, level of support was independent of the children's language, literacy, and cognitive abilities and behavior, indicating inequity of provision.

Law focuses on children and young people with speech, language, and communication needs (SLCN) and concerns about system problems between education and health authorities not collaborating effectively. He suggests that the appropriate support of children and young people with communication support needs is a litmus test for the achievability of inclusion.

Egelund and Dyssegaard in their paper on the inclusion process in Denmark report a number of barriers to successful development of an inclusive system. Some system changes and the use of incentives have been necessary to develop inclusion but they argue that teachers still feel the need of specialist services and resources, and that they have not yet adapted to the idea of inclusion.

Lindner et al. indicate low levels of personalized teaching, a necessary feature of inclusive education, in their study in Germany: a finding from both students' and teachers' perceptions.

Other papers explore the role of other practitioners and approaches to supporting children and young people with SEN. Esposito and Carroll investigated a key post-Warnock development, namely the SENCO, established in 1994 in England to support inclusion. This paper provides evidence that is more positive for the development of inclusion, through examining the assignments during SENCO postgraduate training, which indicated positive engagement with the need for diversity in SENCO practice, meaningful assessment, evidence informed practice, and evaluation of impact.

Vivash and Morgan report a study of the content of psychological advice reports written by educational psychologists. Although these reports did not contribute to the frequent negative use of teaching assistants, namely the "Velcro TA" where TAs are seemingly "tied" to students with SEN, so limiting autonomy, the reports were considered to be characterized by ambiguity; in particular, a focus on what to do but not on how to do it.

Melvin et al. developed a bioecological systems based framework for the understanding of absenteeism from school, both students with SEN or disabilities and typically developing students. Designed to aid researchers, the Kids and Teens at School (KiTes) framework aims to support the development of research which takes into account the complexity of factors relating to school attendance problems. Schuengel et al. provide evidence from a systematic literature search on research using longitudinal designs on the early development of children with intellectual disability.

Finally, Webster reviews the (short) programme of research priorities in the Warnock Report and explores how these compare with subsequent and current research; and with research priorities for the future.

\section{CONCLUSION}

These 16 papers provide a varied set of responses to the development of SEN since the Warnock Report, its conceptualization and practice, and the policy tensions that 
have become evident. Although produced for the system in England, the Warnock Report has been international in its impact. In England and internationally the system and overall financial support for children and young people with special educational needs and disabilities have developed hugely; inclusion has become supported as policy for educational provision; legal frameworks have developed; and research has expanded substantially. Nevertheless, as demonstrated here, there remain major challenges to address if societies are to truly provide appropriate and effective support for our young people with special educational needs and disabilities.

\section{REFERENCES}

Warnock, M. (2005). Special Educational Needs: A New Look. London: Philosophy of Education Society.

Webster, R. (2019). "Interview with Baroness Mary Warnock," in Including Children and Young People with SENs and Disabilities in Learning and Life, ed R. Webster (Abington, PA: Routledge), 11. doi: 10.4324/9780429436499-2

Conflict of Interest: The authors declare that the research was conducted in the absence of any commercial or financial relationships that could be construed as a potential conflict of interest.

\section{AUTHOR CONTRIBUTIONS}

All authors listed have made a substantial, direct and intellectual contribution to the work, and approved it for publication.

\section{ACKNOWLEDGMENTS}

We thank everyone who submitted a paper to this special collection and the reviewers and associate editors who gave their time to ensure the quality of the e-book.
Copyright (c) 2020 Lindsay, Wedell and Dockrell. This is an open-access article distributed under the terms of the Creative Commons Attribution License (CC BY). The use, distribution or reproduction in other forums is permitted, provided the original author(s) and the copyright owner(s) are credited and that the original publication in this journal is cited, in accordance with accepted academic practice. No use, distribution or reproduction is permitted which does not comply with these terms. 